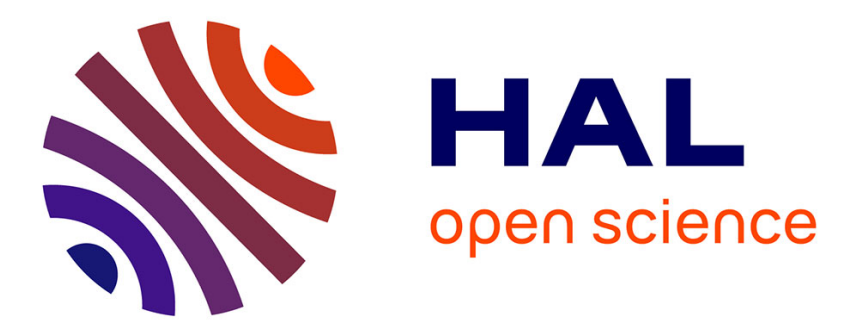

\title{
Phase Transformations of Liquid Drops Containing Mineral Dust and Organic Compound (Citric Acid)
}

Clément Chatre, Corinne Emmelin, Sébastien Urbaniak, Christian Cgo George, Claudia Cogné

\section{To cite this version:}

Clément Chatre, Corinne Emmelin, Sébastien Urbaniak, Christian Cgo George, Claudia Cogné. Phase Transformations of Liquid Drops Containing Mineral Dust and Organic Compound (Citric Acid). Crystal Growth \& Design, 2019, 19 (8), pp.4619-4624. 10.1021/acs.cgd.9b00506 . hal-02270663

\section{HAL Id: hal-02270663 https://hal.science/hal-02270663}

Submitted on 20 Nov 2019

HAL is a multi-disciplinary open access archive for the deposit and dissemination of scientific research documents, whether they are published or not. The documents may come from teaching and research institutions in France or abroad, or from public or private research centers.
L'archive ouverte pluridisciplinaire HAL, est destinée au dépôt et à la diffusion de documents scientifiques de niveau recherche, publiés ou non, émanant des établissements d'enseignement et de recherche français ou étrangers, des laboratoires publics ou privés. 
This document is confidential and is proprietary to the American Chemical Society and its authors. Do not copy or disclose without written permission. If you have received this item in error, notify the sender and delete all copies.

\section{Phase transformations of liquid drops containing mineral dust and organic compound (citric acid)}

\begin{tabular}{|c|c|}
\hline Journal: & Crystal Growth \& Design \\
\hline Manuscript ID & cg-2019-005063.R2 \\
\hline Manuscript Type: & Article \\
\hline $\begin{array}{r}\text { Date Submitted by the } \\
\text { Author: }\end{array}$ & $n / a$ \\
\hline Complete List of Authors: & $\begin{array}{l}\text { Chatre, Clément; Universite Claude Bernard Lyon 1, IRCELYON } \\
\text { Emmelin, Corinne; Universite Claude Bernard Lyon 1, IRCELYON } \\
\text { Urbaniak, Sébastien; Universite Claude Bernard Lyon 1, LAGEPP } \\
\text { George, Christian; CNRS, IRCELYON } \\
\text { Cogne, Claudia; Universite Claude Bernard Lyon 1, LAGEPP }\end{array}$ \\
\hline
\end{tabular}

\section{SCHOLARONE \\ Manuscripts}


KEYWORDS. Ice nucleation, Cristal growth, Calorimetry, Optical cryomicroscopy, Modeling

\begin{abstract}
We investigated the impact of organic matter and mineral particles on atmospheric ice freezing, to better understand the mechanisms of nucleation and crystal growth. Differential scanning calorimetry (DSC) and optical cryomicroscopy have been used to investigate liquid-solid transitions of citric acid aqueous solutions in presence of $1 \mathrm{wt} \%$ of Arizona Test Dust (ATD). These two methods have led to complementary results: DSC enables the quantification of the latent heat and phase transitions, while optical cryomicroscopy allows the in situ observation of freezing phenomena and ice growth rates. Different trends have been observed: (i) ATD facilitates the crystallisation by acting as nuclei centre (NC), the supercooling level decreases of $6^{\circ} \mathrm{C}$ in presence of ATD; (ii) ice crystallisation is affected by the citric acid mass fraction: for concentrations over $50 \mathrm{wt} \%$ crystallisation does not systematically appear during the cooling phase, but during the warming phase, which highlights an amorphous organisation; (iii) there is a threshold of citric acid concentration (around $30 \mathrm{wt} \%$ ) beyond which the ice growth rate significantly decreases. In this work, we have shown that the crystal morphology is linked to the citric acid concentration, and evolves from one nucleation mono-site with continuous framework for low concentrations to multiple sites with multi-branching pattern at high concentrations. A mathematical model is proposed as a first step in the modeling of ice crystal growth in a binary system (water/citric acid) containing mineral particles (ATD), based on the correlation between the ice growth rate and the inverse of the liquid viscosity. These results will be useful for chemical engineering applications and biotechnology, for example, freeze-drying of formulations as well as for better understanding the formation of ice clouds and atmospheric aerosol.
\end{abstract}

\title{
Introduction
}


Understanding the formation of ice in clouds is a critical environmental challenge due to the important implications of water and ice in the Earth's atmosphere (clouds formation, hydrological cycle, radiative balance) and thus in climate. ${ }^{1}$ Despite great advancements in the knowledge of the ice nucleation processes, this subject is still controversial even more for drops containing inorganic or mineral particles (IP, such as desert dust) and oxygenated organic matter (OM). And atmospheric cloud glaciation is not yet very well understood because liquid drops in the atmosphere actually never exist as pure water drops but contain different soluble and insoluble organic and inorganic materials. ${ }^{2}$ A better understanding of the phase state and the surface properties of cloud particles is crucial to foresee the ice particles formation in tropospheric and upper tropospheric clouds and their impact on cloud radiative properties (absorption, reflection, scattering of solar and terrestrial radiations) and physicochemical properties (rate of stratospheric and upper tropospheric heterogeneous reactions). Many difficulties remain to assess the influence of the simultaneous presence of IP and OM during the clouds formation. ${ }^{3}$

Ice nucleation via homogeneous freezing occurs stochastically, at temperatures close to $-38^{\circ} \mathrm{C}$ at atmospheric pressure and relative humidity above $140 \%$ with respect to ice. ${ }^{4}$ In other conditions, ice formation can proceed via heterogeneous nucleation triggered by ice nucleating particles (INPs). ${ }^{5,6}$ In the atmosphere, mineral dusts (and especially desert dust) are recognized as the most important INPs due to their effective ice nucleating ability and their abundance in the atmosphere, with ca. 2000 Tg.year ${ }^{-1}$ being injected into the troposphere. ${ }^{4,7}$ Aqueous droplets containing mineral particles, as INPs, were shown to exhibit more frequent heterogeneous nucleation, requiring lower supersaturation $^{7}$ but what about the drops containing both INPs and oxygenated organic materials? Because the presence of $\mathrm{OM}$ in tropospheric aqueous drops is also indisputable, over 50 wt \% sulfate/organic mixture measured in UT aqueous $\operatorname{drops}^{8}$ and highly water soluble acids, as malic and citric acids, in atmospheric particles. ${ }^{9}$

Currently, the scientific community dealing with high-altitude ice clouds focuses mainly on the initial step of freezing, the ice nucleation ${ }^{10}$. But the way freezing proceeds after ice nucleation is not really considered, although the ice growth process itself drives the phase state and surface properties of resulting cloud particles. ${ }^{1}$ Accordingly, we focused our attention on ice growth and particularly the impact of the presence of both oxygenated organic compounds and mineral particles on water drops freezing. 
We have chosen to investigate the role of a highly water soluble OM, present in the atmosphere ${ }^{11}$, citric acid (solubility $60 \mathrm{wt} \%$, O: C ratio equal to 1.16), with Arizona Test Dust (ATD) and we have provided a relevant model for simulating the resulting crystallisation processes.

\section{Materials \& Methods}

\subsection{Experimental section}

Aqueous solutions of citric acid were prepared at different concentrations [5-60 wt \%] with water Optima ${ }^{\circledR}$ LC/MS, Fischer Scientific, USA. In some experiments, 1 wt \% of Arizona Test Dust (ATD) have been added in the binary solutions. ATD (Powder Technology Inc.) is a proxy for atmospheric mineral composed of $\mathrm{SiO}_{2}(69-77 \%), \mathrm{Al}_{2} \mathrm{O}_{3}(8-14 \%), \mathrm{Fe}_{2} \mathrm{O}_{3}(2-5 \%), \mathrm{Na}_{2} \mathrm{O}(2-4 \%), \mathrm{CaO}$ (2-5\%), $\mathrm{MgO}(1-2 \%), \mathrm{TiO}_{2}(0.5-1.0 \%)$ and $\mathrm{K}_{2} \mathrm{O}(2-5 \%)$. To study the influence of the size of IP, we have used (i) ultrafine ATD Grade A1 (mean particle size: $5 \mu \mathrm{m}$ ) named ultra ATD in the text, and (ii) fine $\operatorname{ATD}(1.5 \mu \mathrm{m} \leq \mathrm{x} \leq 100 \mu \mathrm{m}$ mean particle size: $10 \mu \mathrm{m})$ named normal ATD.

Viscosity measurements of aqueous solutions without ATD have been performed with the MCR 302 rheometer (Anton Paar) provided with a cone plate spindle and a CTD 180 modular temperature device. The temperature range of the experiments was from $-20^{\circ} \mathrm{C}$ to $10^{\circ} \mathrm{C}$, according to the crystallization point of the solutions. At a given temperature, the sample viscosity remains constant in the shear rate range between 0.1 and $100 \mathrm{~s}^{-1}$.

The calorimeter (DSC) used is a Thermal Analysis Instruments (TA Q200) including a refrigerated cooling system with a temperature range from $-80^{\circ} \mathrm{C}$ to $550^{\circ} \mathrm{C}$. A METTLER balance with an accuracy of $\pm 0.01 \mathrm{mg}$ was used to prepare the samples of mass 5-20 mg. The samples were placed in the aluminium pans of volume $40 \mu \mathrm{L}$ and then sealed. During the run, high-purity nitrogen gas was flushed throughout the DSC furnace to avoid condensation. To determine the phase change temperature, the experiments were performed according to the following program: (a) isotherm at $5^{\circ} \mathrm{C}$ during $5 \mathrm{~min}$, (b) cooling rate at $10^{\circ} \mathrm{C} \cdot \mathrm{min}^{-1}$, (c) isotherm at $-70^{\circ} \mathrm{C}$ during $5 \mathrm{~min}$, (d) heating rate at $10^{\circ} \mathrm{C} \cdot \mathrm{min}^{-1}$. All DSC curves were normalized with respect to the sample mass. Cooling rate at $10{ }^{\circ} \mathrm{C} \cdot \mathrm{min}^{-1}$ is much larger than the largest $\left(\sim 80^{\circ} \mathrm{C} /\right.$ hour $)$ atmospheric cooling rates, but Chang et al. ${ }^{12}$ have shown that there were negligible differences between the thermograms obtained at different cooling rates.

The observations in situ of the freezing process were carried out with an optical cryomicroscope LEICA (DM LM) equipped with a Linkam cold stage, and a video capture software at 10 images per 
second. A thin film of the sample solution $(\sim 2 \mu \mathrm{L})$ was placed between two microscope slide coverslips on a sample holder.

The same temperature program as the DSC one was used. Optical cryomicroscope measurements were performed at $10^{\circ} \mathrm{C} \cdot \mathrm{min}^{-1}$, in the temperature range from $20^{\circ} \mathrm{C}$ to $-110^{\circ} \mathrm{C}$. An assessment of ice nuclei numbers, ice growth rate and ice morphology has been performed. Since the crystal growth was restricted by coverslips, optical cryomicroscope observations are mainly two-dimensional ice crystals growth. A polarizer has been used for some photographs.

Images extracted from the optical cryomicroscope videos were analysed by using image processing with ImageJ freeware application. To determine the ice growth rate, the length of ice growth was defined between two pictures. The ice growth rate average has been estimated from a minimum of 20 measures.

\subsection{Numerical section - Growth model}

This section focuses on the numerical equations of the growth model, in order to predict the crystal growth rate. The crystal growth rate is usually described by the product of two terms, a kinetic one $k(T)$ and a thermodynamic one representing the driving force of the crystallization, which corresponds to the difference of chemical potentials of the considered component in liquid and solid phases. In the case of crystallisation from melt by cooling like aqueous solutions, this driving force is a function of the undercooling, which is the difference between the ice melting temperature and the freezing temperature.$^{13}$

The most commonly used models of crystal growth in the literature are expressed as followed (Eq. 1): 14,15

$$
v(T)=k(T)\left[T_{m}-T_{f}\right]^{2}
$$

where $v$ is the growth rate and $T_{m}$ and $T_{f}$ the melting and the freezing temperatures, respectively. The first term $k(T)$ is linked to the mobility of the molecules at a given temperature T. There are different theories to correlate $k$ with the temperature ${ }^{16}$, but in most cases the inverse of the liquid viscosity $\eta(T)$ is assumed to provide a reliable evolution of the molecular mobility ${ }^{17} k(T)$ so that the crystal growth model can be simplified as the following equation (Eq. 2):

$$
v(T)=\frac{a\left[T_{m}-T_{f}\right]^{2}}{\eta(T)}
$$

where $a$ is a constant that can be fitted on experimental data.

\section{Results and discussions}




\subsection{Influence of ATD and citric acid concentration on ice crystallisation}

Figure 1 represents the DSC thermograms of aqueous solutions ranging from 10 to $60 \mathrm{wt} \%$ citric acid with normal ATD. At low concentrations of citric acid (under $40 \mathrm{wt} \%$ ), a single exothermic peak is recorded, highlighting the water crystallization and characterizing a freeze-induced phase separation (FIPS). ${ }^{18}$ Whereas at higher concentrations, the DSC thermograms show a low peak during cooling at $50 \mathrm{wt} \%$, and even none at $60 \mathrm{wt} \%$, characterizing the appearance of an amorphous structure. This is confirmed by a single exothermic peak during warming highlighting a recrystallization.

We agree with the results published by Bogdan et al. ${ }^{18}$ without ATD. Our results show that even with ATD, the freezing temperature is not a monotonic function versus concentration of citric acid. The authors $^{18}$ explained this phenomenon by concentration inhomogeneities in $\mathrm{CA} / \mathrm{H}_{2} \mathrm{O}$, which result from the enhanced tendency of $\mathrm{CA} / \mathrm{H}_{2} \mathrm{O}$ to form molecular CA clusters at low temperature.

The optical cryo-microscopy images of frozen citric acid aqueous solutions confirm the DSC observations, and show how ice morphology changes with increasing concentration. Figure 2a (freezing of $30 \mathrm{wt} \%$ citric acid with ultra ATD) shows that at low concentrations, freezing is always initiated from one INP, and the ice growth is radial from this INP. This INP is however linked to the presence of ultra ATD particles. In contrast, at high concentrations, (Figure 2b, warming of $60 \mathrm{wt} \%$ citric acid with ultra ATD), multiple sites of nucleation can be observed with a dentritic multibranching pattern. There are no multiple ice nucleation events upon warming. Multiple ice nucleation events occur upon cooling, but the ice growth strongly slows down due to increasing viscosity and, ultimately, is terminated completely by liquid-to-glass transition. Upon warming above the glass-toliquid transition, viscosity decreases and at some temperature (note $T_{c}$ in Figure $2 \mathrm{~b}$ ), the minuscule ice crystals, which were formed previously upon cooling, start growing.

FIPS is leading to a continuous ice framework and two freeze concentrated solutions FCS ${ }^{19}$ : (i) one, between the dendrites, maximally freeze-concentrated that interweaves with the ice framework, and (ii) the second one, less concentrated, that envelops the entire ice framework and the first freezeconcentrated solution. We should note that the images presented in this article have been done for a sample volume of around $2 \mu \mathrm{L}$, and the results (specially the crystals morphology) could be different for bigger volume. 

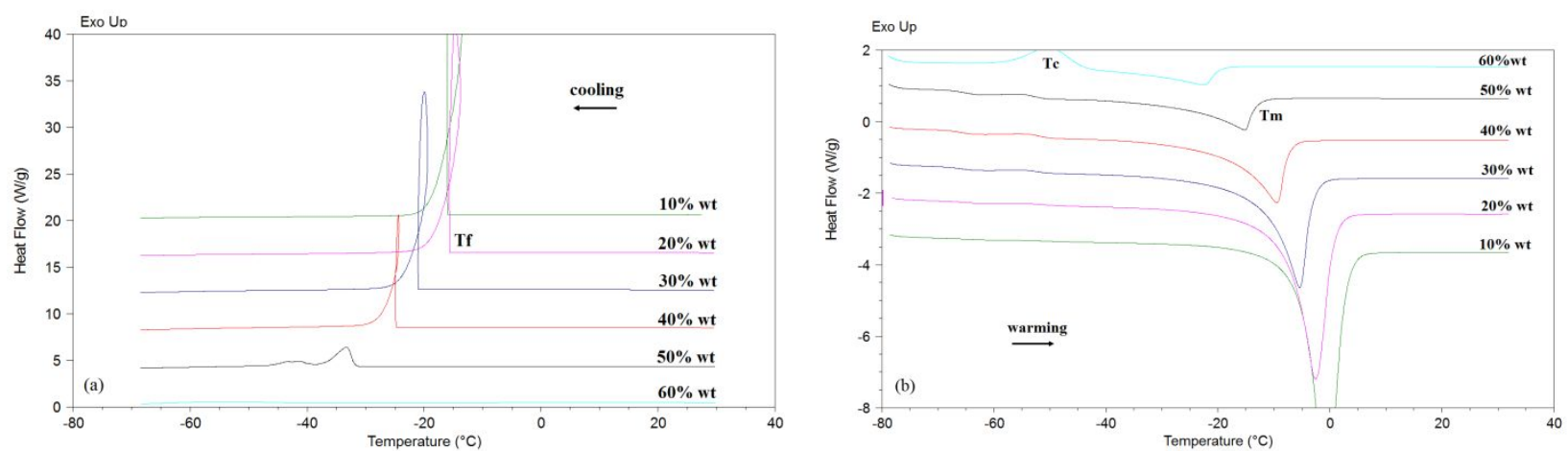

Figure 1. DSC thermograms of $10-60 \mathrm{wt} \%$ citric acid with normal ATD at a scanning rate of 10 ${ }^{\circ} \mathrm{C} . \mathrm{min}^{-1}$ (a) cooling: $\mathrm{T}_{\mathrm{f}}$ represents the freezing temperature, (b) warning: $\mathrm{T}_{\mathrm{m}}$ and $\mathrm{T}_{\mathrm{c}}$ represent the melting end the ice crystallization temperature upon warning, respectively.

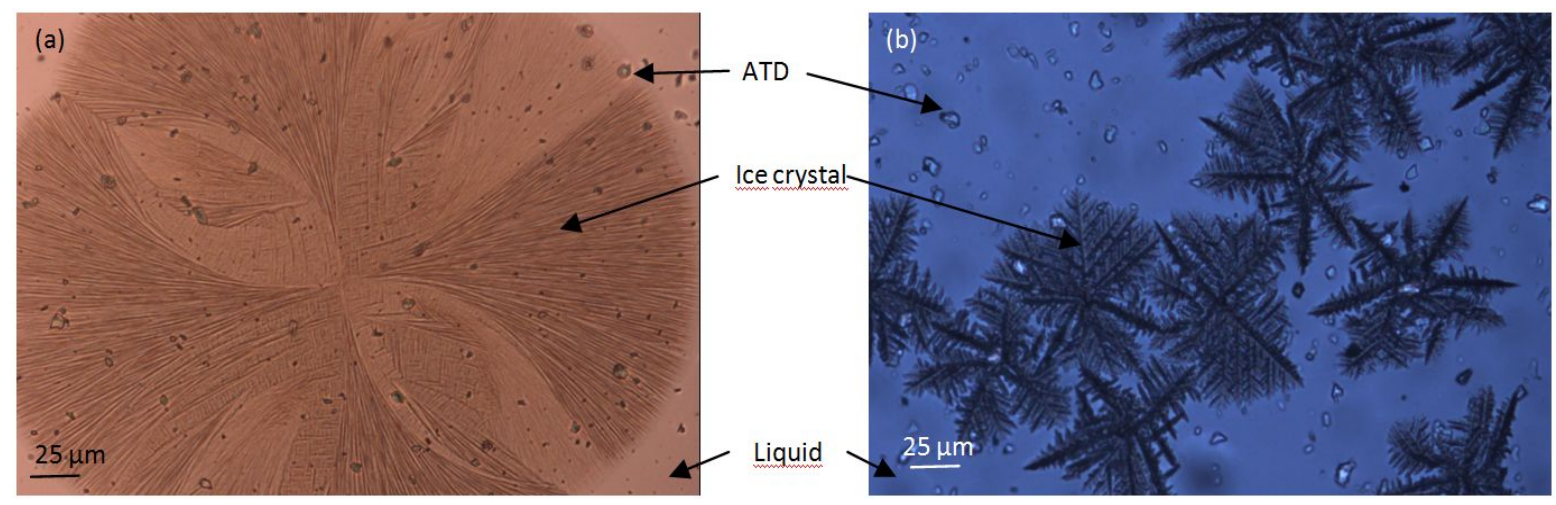

Figure 2. Optical cryo-microscopy images of frozen citric acid aqueous solution with ultra ATD. (a) $30 \mathrm{wt} \%$ citric acid, $\mathrm{T}=-33.30^{\circ} \mathrm{C}$ (upon cooling and without polarizer); (b) $60 \mathrm{wt} \%$ citric acid, $\mathrm{T}=$ $45.90{ }^{\circ} \mathrm{C}$ (upon warming and with polarizer).

Concerning the impact of mineral dust, our results with the optical cryomicroscope show that ATD doesn't affect qualitatively the ice structure. ATD effect is negligible compared to the influence of citric acid concentration but to confirm this hypothesis further experiments with different concentrations of ATD have to be done.

\subsection{Influence of ATD and citric acid concentration on the ice fraction}

Taking into account that ice crystals practically do not contain citric acid, the fraction of frozen water $x_{i c e}$ (ice fraction compared to the total water content of the solution) was calculated using Eq. 3 by integration of the DSC melting peak $\Delta H_{m}$, divided by the ice latent heat of melting $\left(\Delta H_{i c e}\right)$ and normalized by the fraction of total water content $\left(1-x_{c a}\right):{ }^{20}$ 


$$
x_{i c e}=\frac{\Delta H_{m}}{\left(1-x_{C A}\right) \Delta H_{\text {ice }}}
$$

where $\Delta H_{\text {ice }}$ (in $\mathrm{J} \mathrm{g}^{-1}$ ) was calculated from the empirical equation proposed by Riedel ${ }^{21}$ at the melting temperature $\left(T_{m}\right.$ in $\left.{ }^{\circ} \mathrm{C}\right)$ :

$$
\Delta \boldsymbol{H}_{\text {ice }}=333.5+2.05 T_{m}-4.1910^{-3} T_{m}^{2}
$$

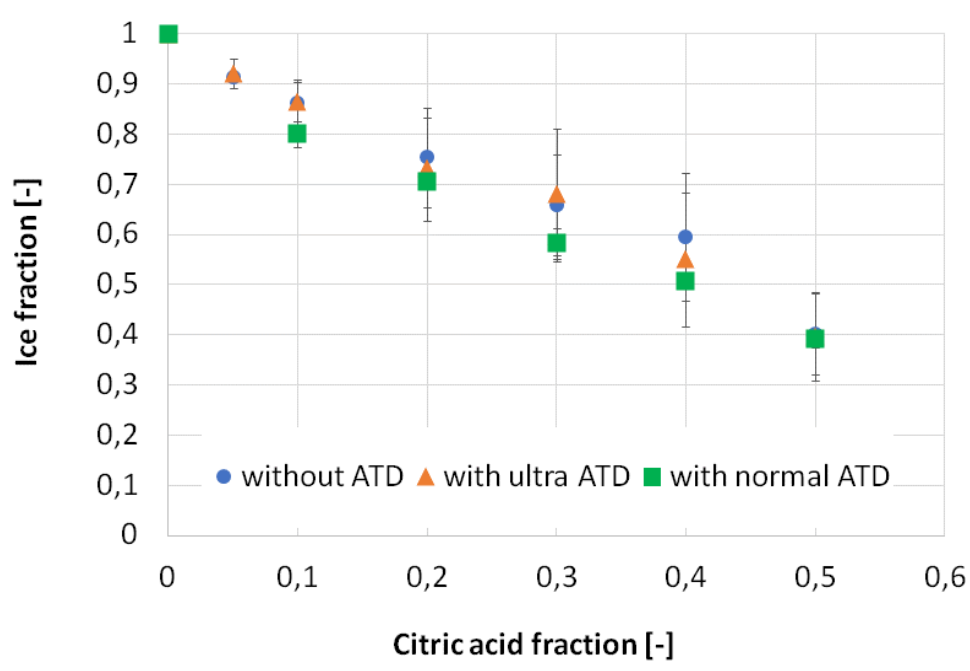

Figure 3. Influence of citric acid fraction and ATD on the fraction of ice.

Figure 3 presents the influence of citric acid concentration and ATD on the fraction of ice in frozen citric acid aqueous solution (from 0 to $50 \mathrm{wt} \%$ ). It seems to demonstrate a linear relationship between the decreasing of the percentage of ice amount versus the increasing of citric acid fraction accounted by the simultaneous increase of the amount of FCS. We can observe that $100 \%$ of total water freeze with distilled water (citric acid fraction equal to 0 ) and this percentage reaches $33 \%$ for citric acid fraction equal to 0.5 after a regular decrease. The commonly advanced explanation is the role of the viscosity: it induces restrictions of the mobility of molecules and sudden glass transitions liquid-solid at low temperatures. Figure 4 presents the influence of citric acid fraction and temperature on viscosity and confirms the increase of the viscosity of the citric acid aqueous solution with the citric acid fraction. But this study must be deepened because increasing citric acid fraction leads to the simultaneous increase of the amount of $\mathrm{FCS}^{18}$ and consequently could lead to the fraction of frozen water decreases.

Moreover, in figure 3, the same results are obtained without ATD and with ultrafine ATD and with normal ATD. The curve obtained with the normal ATD shows a shift of about ten percent but the 
results are quite close to the error bars and it would be tricky to attribute this difference of the amount of frozen water to water captured by the normal ATD. In conclusion, it suggests that mineral dust does not impact significantly the amount of frozen water. But to confirm this hypothesis, it would be necessary to do some experiments with different amount of ATD and with other size of dusts.

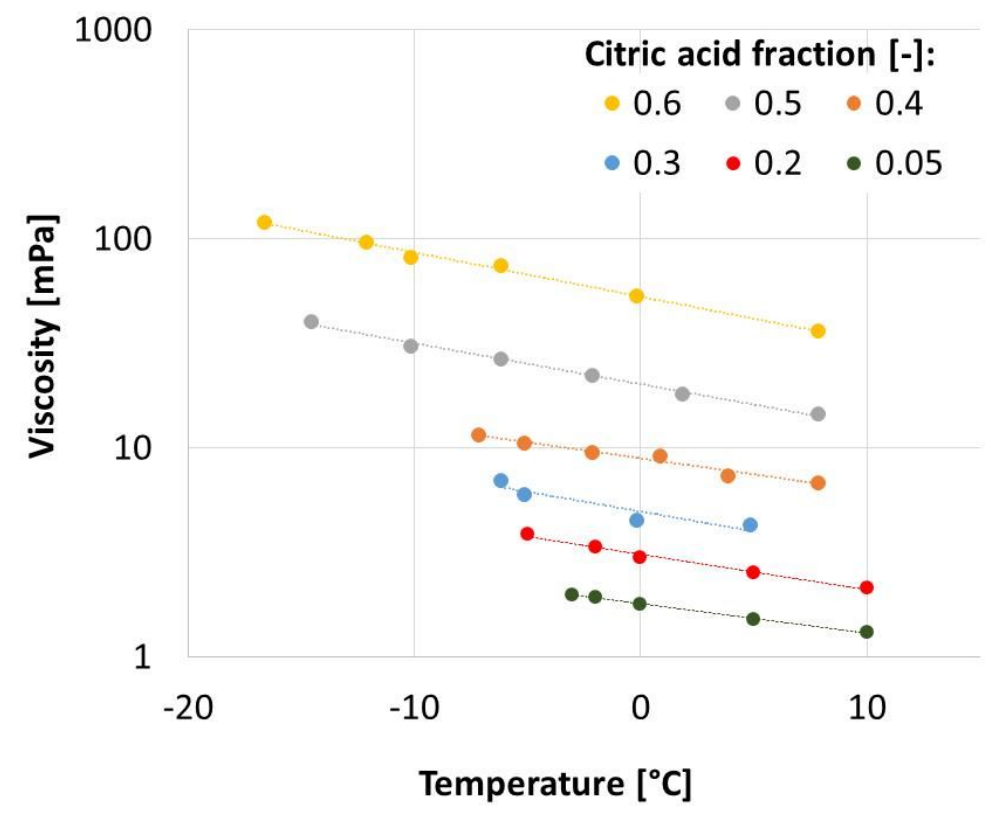

Figure 4. Influence of citric acid fraction and temperature on viscosity in a semilog plot (without ATD).

\subsection{Influence of ATD and citric acid concentration on undercooling temperature}

The impact of citric acid concentration, up to $50 \mathrm{wt} \%$, and the presence of ATD on the undercooling ability have been studied by lowering the temperature of citric acid solutions (i) without ATD, (ii) with normal ATD and (iii) with ultra ATD below their freezing points. Figure 5 presents the undercooling level $\Delta \mathrm{T}$, corresponding to the difference between the melting and the freezing temperatures $\left(\Delta \mathrm{T}=T_{m}-T_{f}\right)$. The experiments were repeated at least 5 times and a good reproducibility was obtained. 


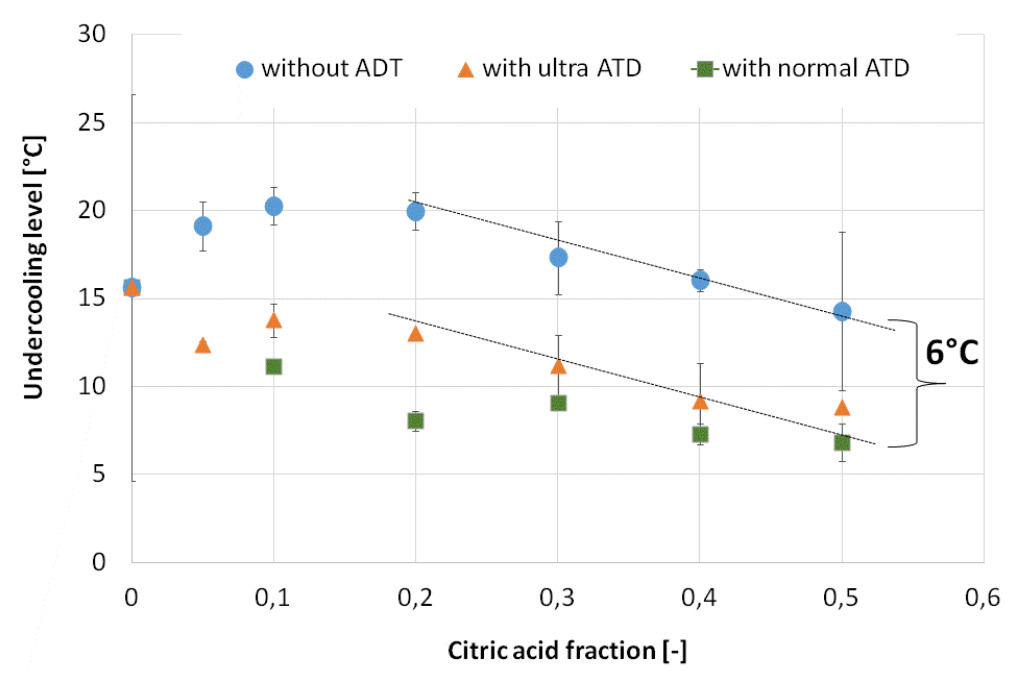

Figure 5. Influence of citric acid fraction and ATD on undercooling level.

Figure 5 shows that the presence of citric acid creates undercooling level. From 0.05 to 0.1 citric acid fraction, undercooling level increases with citric acid concentration. But above 0.2 citric acid fraction, the undercooling level obviously decreases with the concentration.

Concerning ATD, Figure 5 shows the role of mineral dust on the undercooling ability of citric acid aqueous solution. ATD decreases the undercooling level around $6{ }^{\circ} \mathrm{C}$, highlighting that ATD can initiate nucleation and facilitate the formation of INP. The experiments with two particles sizes (normal and ultra ATD) showed that ATD size has no significant effect on the undercooling level. The effect remains constant whatever the dust size in the range of ultra and normal ATD. This observation had to be extended to studies with a wider range of particle sizes.

Optical cryomicroscopy (figure 6) confirms the role of ATD on the nucleation, because statistically the nucleation sites are very often centered on ATD particles.
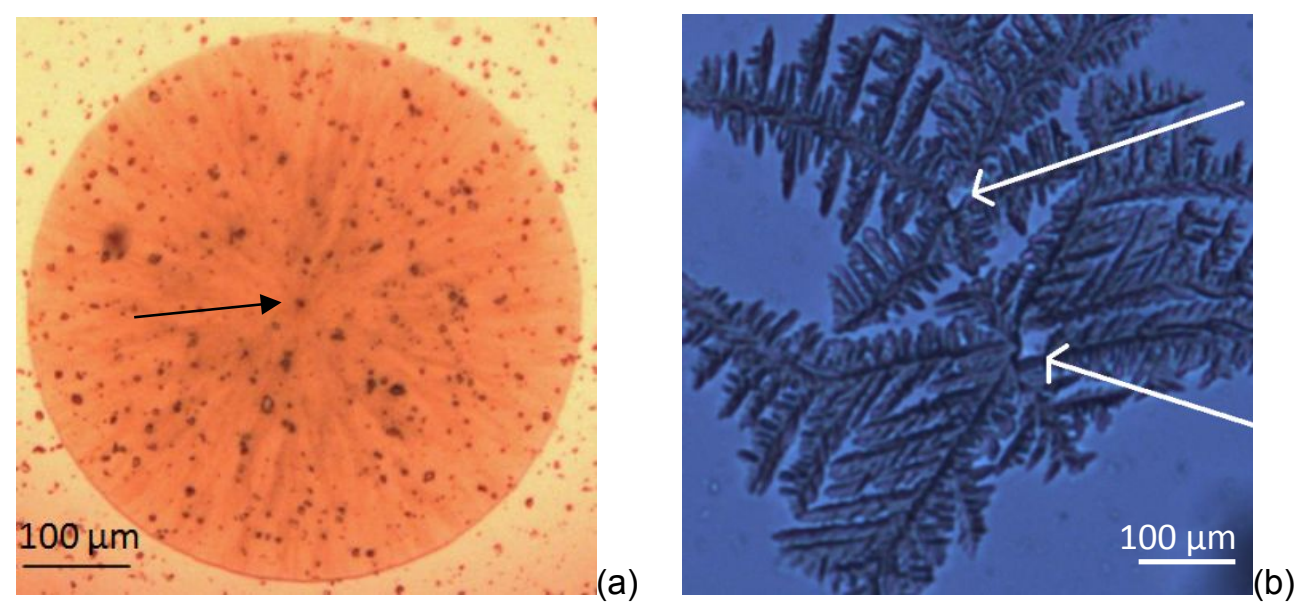
Figure 6. Optical cryomicroscopy photographs focus on the crystal centre, the arrows indicate ATD particles. (a) 40 wt $\%$ citric acid with ultra ATD, $\mathrm{T}=-37.50{ }^{\circ} \mathrm{C}$ (without polarizer); (b) 60 wt \% citric acid with ultra ATD, $\mathrm{T}=-48.00{ }^{\circ} \mathrm{C}$ (upon warming and with polarizer).

\subsection{Modelling of the crystal growth rate}

Our study has showed the joint impact of citric acid concentration and ATD on ice crystallisation. To model the ice growth rate, we firstly need to fit the experimental viscosity data (shown on figure 4) as an exponential function of the temperature for the different citric acid concentrations (Reynold's $\left.\operatorname{model}^{22}\right)$ :

$$
\eta(T)=A e^{-B T}
$$

where $\eta$ is the liquid viscosity in $\mathrm{mPa} . \mathrm{s}, T$ is the temperature in ${ }^{\circ} \mathrm{C}, A$ and $B$ are parameters given in Table 1. These parameters have been fitted on experimental data by minimizing the sum of squared deviations between the model and the experimental data.

Table 1. Fitting exponential coefficient of viscosity (mPa.s) from Equation 5.

\begin{tabular}{|c|c|c|c|c|}
\hline \multirow{2}{*}{$\begin{array}{l}\text { Citric acid } \\
\text { fraction [-] }\end{array}$} & \multicolumn{2}{|c|}{$\begin{array}{l}\text { Fitting exponential } \\
\text { coefficient }\end{array}$} & \multirow{2}{*}{$\begin{array}{c}\text { Temperature range of the } \\
\text { experimental data }\left[{ }^{\circ} \mathrm{C}\right]\end{array}$} & \multirow{2}{*}{$\begin{array}{c}\text { Standard deviation } \\
\text { with experimental data } \\
{[-]}\end{array}$} \\
\hline & $\mathrm{A}[\mathrm{mPa} . \mathrm{s}]$ & $\mathrm{B}\left[{ }^{\circ} \mathrm{C}^{-1}\right]$ & & \\
\hline 0.05 & 1.793 & $3.22410^{-2}$ & {$[-3 ; 10]$} & 0.9992 \\
\hline 0.2 & 3.093 & $-3.89910^{-2}$ & {$[-5 ; 10]$} & 0.9906 \\
\hline 0.3 & 4.963 & $-4.35110^{-2}$ & {$[-6.5 ; 5]$} & 0.8798 \\
\hline 0.4 & 8.918 & $-3.54210^{-2}$ & {$[-7.5 ; 8]$} & 0.9672 \\
\hline 0.5 & 2.019 & $-4.50510^{-2}$ & {$[-15 ; 8]$} & 0.9941 \\
\hline 0.6 & 5.290 & $-4.85810^{-2}$ & {$[-17 ; 8]$} & 0.9946 \\
\hline
\end{tabular}

It is worth noting that experimental data of ice growth rate have been measured at the freezing temperature of the solution, so the viscosity data has been extrapolated to colder temperature over the temperature range of the experimental data.

The knowledge of the viscosity allowed us to predict the ice growth rate according to the equation 2 . 

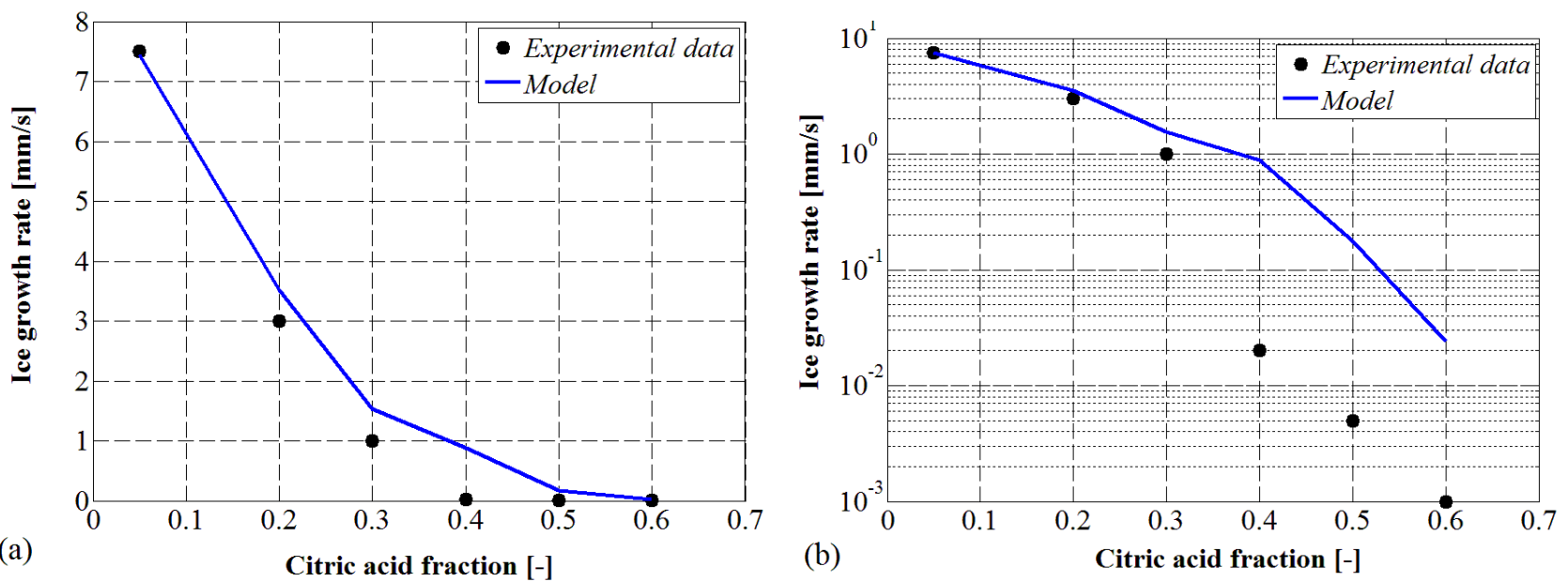

Figure 7. Influence of citric acid fraction on the ice growth rate. Black point: experimental data; Blue line: model. (a) Classical scale; (b) Semi-log scale.

In Figure $7 \mathrm{a}$, one can see a strong decrease of ice growth rate with increasing concentration, as mentioned by Bogdan ${ }^{2}$ who specified that the freezing process could be completely stopped by the glass transition at some high concentrations. The model's constant has been fitted on the experimental data by minimizing the sum of squared deviations between the model and the experimental data. In these conditions, the ice growth rate could be predicted with a quite good accuracy by the following equation (Eq. 6):

$$
v(T)=\frac{2.6310^{-2}}{\eta(T)}\left[T_{m}-T_{f}\right]^{2}
$$

with the viscosity $\eta$ in Pa.s and the ice growth rate $v$ in $\mathrm{mm} \cdot \mathrm{s}^{-1}$. However, in a semi-log scale representation (Figure $7 \mathrm{~b}$ ), one can see that the experimental growth rate is very much reduced compared to the predicted one, upper a fraction around 0.3. In this range, the growth dynamics are not be well described simply by the inverse of the liquid viscosity.

\section{Conclusions}

In this work, we have used DSC and optical crymicroscopy for the study of the impact of mineral particles (ATD) and citric acid concentration on freezing and glass transition that occur upon cooling and warming of $\mathrm{H}_{2} \mathrm{O}$ /citric-acid.

The two methods have been used to analyze the mechanisms of nucleation and crystal growth and have given complementary results. DSC allows measuring quantitative data, like freezing or melting temperature, and the amount of energy releases during the phase change. The optical cryomicroscopy allows to visualize the nucleation centres and the ice morphogenesis but also to measure ice propagation velocities. 
The principal results highlighted by our study are (i) the confirmation of the impact of citric acid, on the crystallisation temperature of water, on the ice growth rate and on the structure of the ice network (ii) the impact of mineral dust on aqueous solutions by decreasing significantly the undercooling level (around $6{ }^{\circ} \mathrm{C}$ ) and acting as a precursor of nucleation (iii) the presence of mineral dust does not impact the ice growth rate or the structure of the ice network.

We have proposed a mathematical model based on the correlation of the ice growth rate with the viscosity of the solution. This model needs improvements but gives a good representation of the link between the freezing rate and the increase of the citric acid concentration.

To better understand the role of mineral dust, next steps of this study will include experiments on aqueous solutions of OM containing: (i) different fractions of ATD, (ii) different size of ATD, (iii) different compositions of mineral dust.

Our results on the impact of mineral impurities on the phase transition may be of interests for fields of atmospheric chemistry, but also food processes and crystallisation applications.

Our study demonstrates that DSC thermograms and optical cryomicroscope are complementary and allow to extract important information.

ACKNOWLEDGMENT. The authors are grateful to the federation IngeLyse and the Institut de Chimie de Lyon (ICL) for the financial support received during this work.

This work was performed within the framework of the EUR $\mathrm{H}_{2} \mathrm{O}$ 'Lyon (ANR-17-EURE-0018) of Universite de Lyon (UdL), within the program "Investissements d'Avenir" operated by the French National Research Agency (ANR).

\section{AUTHOR INFORMATION}

\section{Corresponding Author}

*claudia.cogne@univ-lyon1.fr

\section{References}

[1] Bogdan, A.; Molina, M.J. Physical chemistry of the freezing process of atmospheric aqueous drops. J. Phys. Chem. A 2017,121, 3109-3116. DOI: 10.1021/acs.jpca.7b02571

[2] Bogdan, A. Ice Clouds: Atmospheric Ice Nucleation Concept versus the Physical Chemistry of Freezing Atmospheric Drops, J. Phys. Chem. A 2018, 122, 7777-7781. DOI: 10.1021/acs.jpca.8b07926 
[3] Knopf, D.A.; Alpert, P.A.; Wang, B. The Role of Organic Aerosol in Atmospheric Ice Nucleation: A Review, ACS Earth Space Chem. 2018, 2, 168-202. DOI: 10.1021/acsearthspacechem.7b00120

[4] Kanji, Z.A.; Ladino, L.A.; Wexc, H.; Boose, Y.; Burkert-Kohn, M.; Cziczo, D.J.; Krämer, M. Overview of Ice Nucleating Particles, Meteor. Monogr. 2017, 58, Amer. Meteor. Soc. DOI: 10.1175/AMSMONOGRAPHS-D-16-0006.1

[5] Bertram, A.K.; Koop, T.; Molina, L.T.; Molina, M.J. Ice formation in (NH4)2SO4H2O particles, J. Phys. Chem. A 2000, 104, 584-588. DOI: 10.1021/jp9931197

[6] Zuberi, B.; Bertram, A.K.; Koop, T.; Molina, L.T.; Molina, M.J. Heterogeneous freezing of aqueous particles induced by crystallized $\left(\mathrm{NH}_{4}\right)_{2} \mathrm{SO}_{4}$, ice, and letovicite, Phys. Chem. A 2001, 105, 6458-6464. DOI: 10.1021/jp010094e

[7] Hoose, C.; Möhler, O. Heterogeneous ice nucleation on atmospheric aerosols: a review of results from laboratory experiments, Atmos. Chem. Phys. 2012, 12, 9817-9854. DOI: 10.5194/acp-129817-2012

[8] Froyd, K.D.; Murphy, D.M.; Sanford, T.J.; Thomson, D.S.; Wilson, J.C.; Pfister, L.; Lait, L.; Aerosol Composition of the Tropical Upper Troposphere, Atmos. Chem. Phys. 2009, 9, 4363-4385.

[9] Kawamura, K.; Ikushima, K. Seasonal changes in the distribution of dicarboxylic acids in the urban atmosphere, Environ. Sci. Technol. 1993, 27, 2227-2235. DOI: 10.1021/es00047a033

[10] Bogdan, A.; Molina, M.J. Formation of High-Altitude Ice Clouds: Ice Nucleation or Freezing? $96^{\text {th }}$ American Meteorological Society Annual Meeting, 9-14 ${ }^{\text {th }}$ January 2016.

[11] Jung, J.; Kawamura K. Enhanced concentrations of citric acid in spring aerosols collected at the Gosan background site in East Asia, Atmos. Environ. 2011, 45, 5266-5272. DOI:10.1016/j.atmosenv.2011.06.06

[12] Chang, H.Y.; Koop, T.; Molina, L.T.; Molina, M.J. Phase transitions in emulsified $\mathrm{HNO}_{3} / \mathrm{H}_{2} \mathrm{O}$ and $\mathrm{HNO}_{3} / \mathrm{H}_{2} \mathrm{SO}_{4} / \mathrm{H}_{2} \mathrm{O}$ solutions, J. Phys. Chem. A. 1999, 103, 2673-2679. DOI : $10.1021 /$ jp9841034.

[13] Kashchiev D., Nucleation: Basic Theory with Applications, Butterworth-Heinemann, Boston, 2000 .

[14] Eskin, D.; Mi, J. Solidification Processing of Metallic Alloys Under External Fields, Springer Series in Materials Science, 2018. ISBN 978-3-319-94842-3

[15] Zaritzky, N. Physical-chemical principles in freezing. In D.-W. Sun (Ed.), Handbook of frozen food packaging and processing. Boca Raton, FL: Taylor \& Francis, 2006.

[16] Sun, G.; Xu, J.; Harrowell P. The mechanism of the ultrafast crystal growth of pure metals from their melts, Nat. Mater. 2018, 17, 881-886. DOI: 10.1038/s41563-018-0174-6 
[17] Gerges, J.; Affouard, F. Predictive Calculation of the Crystallization Tendency of Model Pharmaceuticals in the Supercooled State from Molecular Dynamics Simulations, J. Phys. Chem. B 2015, 119, 10768-10783. DOI: 10.1021/acs.jpcb.5b05557

[18] Bogdan, A.; Molina, M.J.; Tenhu, H.; Loerting, T. Multiple Glass Transitions and Freezing Events of Aqueous Citric Acid, J. Phys. Chem. A 2015, 119, 4515-4523. DOI: 10.1021/jp510331h

[19] Bogdan, A.; Molina, M.J.; Tenhu, H.; Bertel, E.; Bogdan, N.; Loerting, T. Visualization of Freezing Process in situ upon Cooling and Warming of Aqueous Solutions, Scientific Reports 4 2014, 1-10. DOI: 10.1038/srep07414

[20] Cogné, C.; Andrieu, J.; Laurent, P.; Besson, A., Nocquet, J. Experimental data and modelling of thermal properties of ice creams, J Food Eng 2003, 58, 331-341. DOI: 10.1016/S02608774(02)00396-5

[21] Riedel L. Eine formel zur Berechnung der enthalpie fettarmer Lebensmittel in Abhängigkeit von Wassergehalt und Temperatur. Mikrobiologie Technologie der Lebensmittel, 5, 129-133, 1978.

[22] Ellahi, R.; Raza, M.; Vafai, K. Series solutions of non-Newtonian nanofluids with Reynolds' model and Vogel's model by means of the homotopy analysis method, Math Comput Modell 2012, 55, 1876-1891. DOI: 10.1016/j.mcm.2011.11.043 


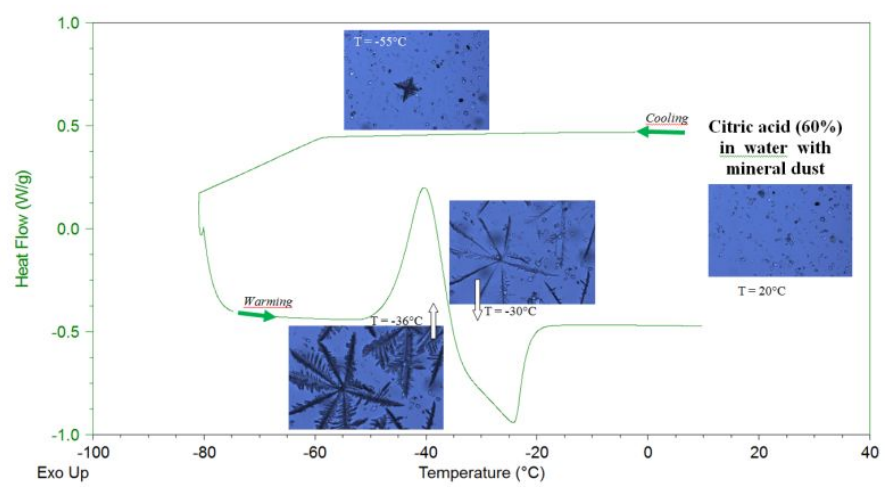

